\title{
Alternative hybrid and staged interventional treatment of congenital heart defects in critically ill children with complex and non-cardiac problems
}

\author{
Ireneusz Haponiuk ${ }^{1,2}$, Maciej Chojnicki², Radosław Jaworski², Mariusz Steffens ${ }^{2}$, Aneta Szofer-Sendrowska², \\ Konrad Paczkowski², Ewelina Kwaśniak ${ }^{2}$, Jacek Zieliński ${ }^{3}$, Katarzyna Gierat-Haponiuk ${ }^{4}$, Katarzyna Leszczyńska ${ }^{5}$ \\ ${ }^{1}$ Chair of Physiotherapy, Gdansk University of Physical Education and Sport, Gdansk, Poland \\ 2Department of Pediatric Cardiac Surgery, Mikolaj Kopernik Hospital, Gdansk, Poland \\ ${ }^{3}$ Department of Oncological and Plastic Surgery, Medical University of Gdansk, Gdansk, Poland \\ ${ }^{4}$ Department of Rehabilitation, Medical University of Gdansk, Gdansk, Poland \\ ${ }^{5}$ Department of Obstetrics, Medical University of Gdansk, Gdansk, Poland
}

Videosurgery Miniinv 2015; 10 (2): 244-256

DOI: $10.5114 /$ wiitm.2015.49474

\begin{abstract}
Introduction: An individually designed strategy of comprehensive alternative hybrid and staged interventional treatment (AHASIT) can be a reasonable alternative to conventional treatment of congenital heart defects, reduce the risk of cardiac surgery or interventions performed separately, and give an additional chance for critically ill children. Aim: To present our experience and the results of AHASIT of severely ill or borderline children referred for surgery with the diagnosis of congenital heart defects.

Material and methods: A group of 22 patients with complex cardiac and non-cardiac pathologies was retrospectively selected and analyzed. An individual preoperative severity scale was established for AHASIT patients, with one point for each of the following preoperative complications: prematurity, low body weight, cyanosis, intolerance to drug therapy, failed interventional treatment prior to admission, mechanical ventilation prior to the procedure, chronic respiratory failure and non-cardiac, mainly congenital malformations (congenital diaphragmatic hernia, lower extremity agenesia, duodenal atresia) and acquired problems (newborn edema, necrotic enterocolitis, intracranial hemorrhage, liver and renal failure, anemia and thrombocytopenia, infections or colonization with drug-resistant pathogens).

Results: The analysis of the postoperative course showed that the patients with 5 AHASIT points or more had a more complicated postoperative course than the patients with 1 to 4 AHASIT points.

Conclusions: The AHASIT of pediatric congenital heart defects with complex and non-cardiac problems appeared to be an attractive option for selected severely ill patients. The strategy was found to be effective in selected neonates suffering from complex and accompanying non-cardiac pathologies, with positive final results of both cardiological intervention and planned surgery.
\end{abstract}

Key words: cardiac surgery, interventional cardiology, transcatheter, hybrid technique, newborn.

\section{Introduction}

Patients with congenital heart defects usually suffer from a variety of complex cardiovascular dis- orders and concomitant non-cardiac problems. The complexity of accompanying diseases could affect the treatment plans and therapeutic strategies, un-

\section{Address for correspondence}

Ireneusz Haponiuk PhD, Department of Pediatric Cardiac Surgery, Mikolaj Kopernik Hospital, 1-6 Nowe Ogrody St, 80-803 Gdansk, Poland, phone: +48 5876404 90, e-mail: ireneusz_haponiuk@poczta.onet.pl 
less it crosses the threshold of 'acceptable' risk for cardiac surgery or percutaneous interventions. Great efforts are made to qualify patients with congenital heart defects in their optimal condition with circulatory compensation and medical fixation of accompanying deficiencies. In emergency settings, decompensated cardiac problems render impossible the treatment in a conventional manner. Typically predictive procedures could result in atypical but predictable complications in sub-compensated critically ill patients. Unfortunately, in some children the evaluation of risk due to poor general condition and concomitant problems preclude conventional treatment for congenital heart defects [1].

Comprehensive alternative hybrid and staged interventional treatment (AHASIT) with an option of forthcoming surgical procedures can be a reasonable alternative to conventional treatment of congenital heart defects in patients with complex cardiac and non-cardiac problems. An individually designed strategy of hybrid or interventional treatment could reduce the risk of cardiac surgery or interventions performed separately, and give an additional chance for critically ill children with complex congenital heart defects [2]. The potential of avoiding cardiopulmonary bypass, peripheral vascular access limitations and hemodynamic instability related to transcatheter closure in pediatric patients are the advantages that make this option attractive for borderline patients and children with severe non-cardiac problems [3].

Hybrid cardiac procedures are modern techniques that rely on the cooperation of cardiac surgeons with interventional cardiologists performing their basic skills in a common operative theatre. On the other hand, interventional percutaneous procedures prove their great effectiveness in well-established areas, in which they support or eliminate the need of surgery, and provide better results $[1,4]$.

Growing experience naturally results in an observable tendency to broaden cooperative cardiovascular strategies to include potentially extremely high-risk children, suffering from prematurity, low body weight, newborn edema, intracranial hemorrhage, cyanosis with intolerance to drug therapy, or cardiogenic shock. In accordance with hybrid and interventional treatment, there seems to be an achievable method also for patients for whom new therapies are the only chance, despite their borderline poor general condition that precludes conventional management.
We focused on exceptionally risky children who underwent an alternative hybrid and staged interventional treatment in our institution. The severity of their preoperative clinical condition made us modify our routine strategies. In order to create a new approach for borderline patients and provide an acceptable therapeutic option for complex problems, we decided to broaden the inclusion criteria despite being fully aware of the extreme risk.

\section{Aim}

The aim of the study was to present our institutional experience and the results of AHASIT of severely ill or borderline children referred for surgery with the diagnosis of congenital heart defects.

\section{Material and methods}

A group of 22 patients with complex cardiac and non-cardiac pathologies was retrospectively selected from the whole group of 109 consecutive patients who underwent hybrid treatment in Department of Pediatric Cardiac Surgery in the period from 1.01.2008 to 4.09.2014. We performed the analysis with the focus on borderline children with complex cardiac and accompanying non-cardiac problems in the group of patients referred for AHASIT.

The patients included in the group were treated with different strategies in order to provide a definitive or a staged solution of complex cardiovascular problems. The main types of procedures performed in selected clinical problems were as follows:

1. Closure of intracardiac defects of unsuitable localization or atypical clinical presentation of the patient (difficult peripheral vascular access, anomalies of systemic venous return, congenital anomalies of the chest structure) (Photo $1 \mathrm{~A}$ ).

2. Stenting of the patent arterial duct (PDA) in duct-dependent circulation: systemic and pulmonary (Photo $1 \mathrm{~B}$ ).

3. Peripheral percutaneous and surgical approach (lateral thoracotomy) stenting of pulmonary arteries before, or late after the correction of right heart lesions (tetralogy of Fallot, pulmonary atresia) using artificial or biological implants (xenografts) (Photo $1 \mathrm{C}$ ).

4. Aortic coarctation or aortic arch stenosis in critically ill newborns (Photo $1 \mathrm{D}$ ).

5. Improvement of an interatrial shunt in single ventricle staged treatment (Fontan principle). 

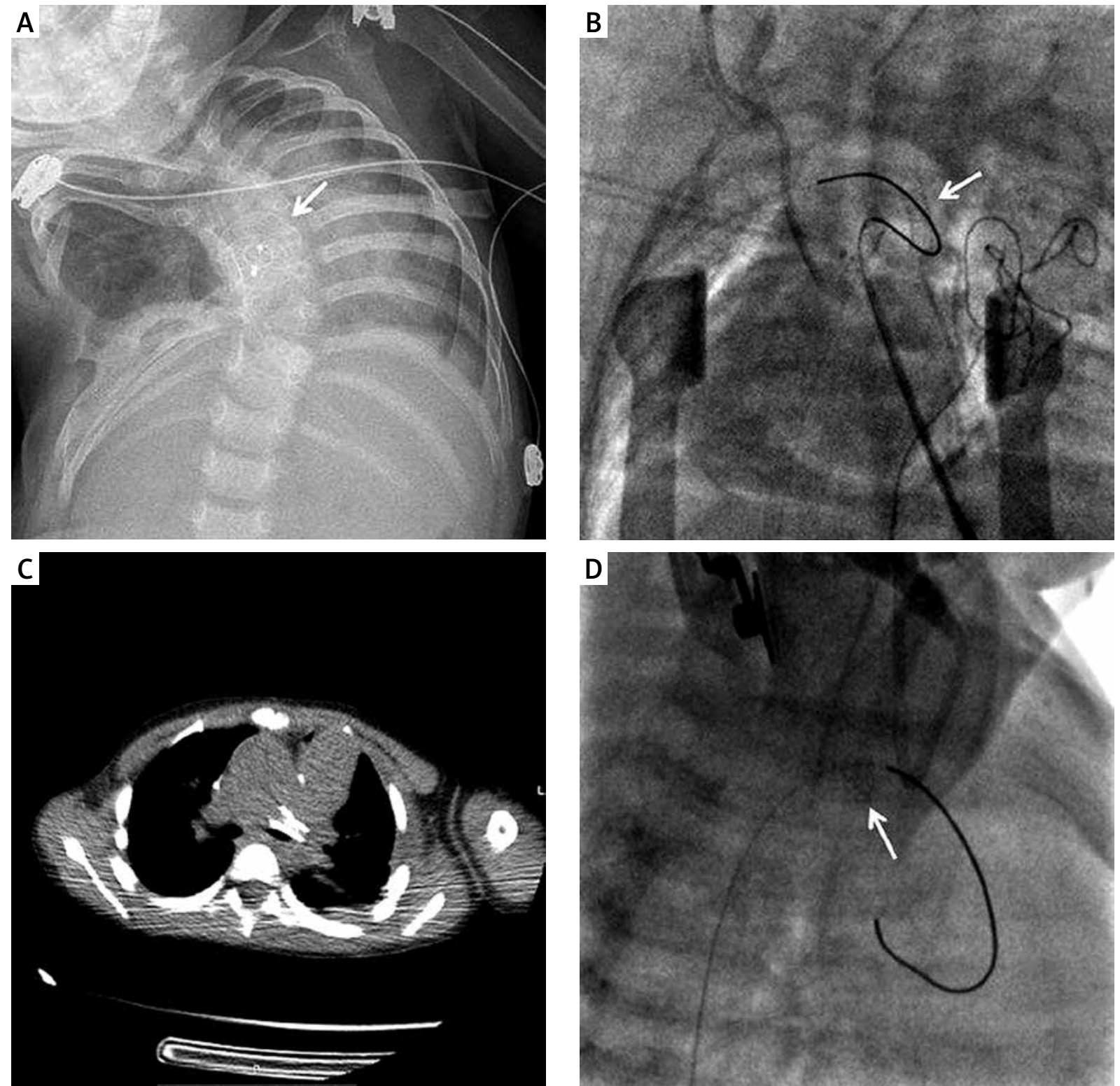

Photo 1. A - Postoperative chest X-ray of the patient after a hybrid ASD closure: 2-year-old girl with secundum ASD and congenital malformation of the chest (severe scoliosis, sternal deformation, right-sided agenesia of the ribs) with anomalous systemic venous return: discontinuation of inferior caval vein with drainage to the coronary sinus. Right anterior minithoracotomy approach, note the septal occluder implanted via atrial wall puncture (arrow). B - Intraoperative view: direct PDA-stent implantation in a $1.8 \mathrm{~kg}$ premature child with interrupted aortic arch (IAA type C) after initial selective LPA and RPA bandings. C - Chest tomography: 5 -year-old boy 5 days after peripheral surgical approach (left lateral thoracotomy) with recruitment of primary occluded left BT shunt for stenting of left main pulmonary artery stenosis late after the correction of pulmonary atresia using full-size valved xenograft (Contegra No. 12, Medtronic, USA). D - Exit angiography: stenting of the proximal aortic arch stenosis in hypotrophic 5-week-old infant (2 kg bw) with tetralogy of Fallot, who finally underwent anatomic correction of ToF with simultaneous removal of the stent and surgical aortic plasty, ECC with deep hypothermia (DHCA) was used 
The analyzed data were retrospectively selected from our institutional database which includes surgical, interventional and hybrid patients, following the AHASIT inclusion criteria. The endpoint of the observation was the date of the last outpatient follow-up or retrieving the data from the database of the department.

The inclusion criteria for the AHASIT group were congenital cardiac defect with accompanying comorbidities: low body weight, prematurity, cardiac sub-compensation prior to the hybrid procedure, a history of cardiopulmonary resuscitation related to the worsening of general condition, complex cardiovascular pathologies (complex cardiac disease with central and peripheral vascular anomalies), emergency settings due to failed interventional procedures or bad response to medical treatment (cat- echolamines, intolerance to prostaglandins). The criteria for exclusion were: 'classic' and planned hybrid treatment in a scheduled manner, conventional cardiac surgery and percutaneous interventional treatment when performed as separate procedures. We also excluded from the analysis patients referred for planned hybrid treatment without additional problems (muscular ventricular septal defects - mVSDs), whose data were analyzed and presented in our previous papers $[5,6]$.

For the purpose of further analysis the patients were initially divided into two age groups: group 1 - newborns (age up to 30 days), and group 2 - infants and older children (age more than 30 days). The general characteristics of the patients from the analyzed group with major preoperative problems are presented in Table I. We retrospectively analyzed

Table I. Patients' general characteristics with symptoms of accompanying problems and an initial division into two subgroups: newborns, and infants and children older than 12 months

\begin{tabular}{|c|c|c|c|}
\hline Feature & $\begin{array}{l}\text { Number }(\%) / \text { mean } \\
\text { (SD; range }) \text { - total } \\
(n=22) \\
\text { General }\end{array}$ & $\begin{array}{c}\text { Number }(\%) / \text { mean } \\
\text { (SD; range })- \text { newborns } \\
(n=8) \\
\text { Group } 1\end{array}$ & $\begin{array}{l}\text { Number }(\%) / \text { mean } \\
\text { (SD; range) - infants } \\
\text { and older children } \\
(n=14) \\
\text { Group } 2\end{array}$ \\
\hline Gender (male/female) & $10(45.5 \%) / 12(54.5 \%)$ & $3(13.6 \%) / 5(22.7 \%)$ & $7(50 \%) / 7(50 \%)$ \\
\hline Age [months] & $25.5(47.2 ; 0.03-194)$ & $\begin{array}{c}0.47, \text { median } 0.52 \\
(0.29 ; 0.03-0.87)\end{array}$ & $\begin{array}{c}\text { 39.7, median } 13.1 \\
(54.7 ; 2.7-194)\end{array}$ \\
\hline Body weight $[\mathrm{kg}]$ & $9.5(12.1 ; 1.8-50)$ & $2.5(0.56 ; 1.8-3.2)$ & 13.5, median $7.4(2.9-50)$ \\
\hline Prematurity (< 38 weeks gestational age) & $7(31.8 \%)$ & 2 & 5 \\
\hline Low birth weight $(<2.5 \mathrm{~kg})$ & $10(45.5 \%)$ & 6 & 4 \\
\hline Perinatal infection & $6(27.3 \%)$ & 2 & 4 \\
\hline Respiratory failure & $9(40.9 \%)$ & 5 & 4 \\
\hline Cyanosis & $13(59.1 \%)$ & 5 & 8 \\
\hline Low body weight & $11(50 \%)$ & 6 & 5 \\
\hline Coarctation of the aorta & $3(13.6 \%)$ & 0 & 3 \\
\hline Congenital diaphragmatic hernia (CDH) & $2(9.1 \%)$ & 2 & 0 \\
\hline Genetic syndrome & $6(27.3 \%)$ & 1 & 5 \\
\hline Thymus gland agenesia & $4(18.2 \%)$ & 2 & 2 \\
\hline $\begin{array}{l}\text { History of an emergency cardiac, } \\
\text { interventional or surgical } \\
\text { procedure in newborn }\end{array}$ & $9(40.9 \%)$ & 3 & 6 \\
\hline Single ventricle circulation (SV) & $5(22.7 \%)$ & 4 & 1 \\
\hline Follow-up [months] & $18.7(16.3 ; 0-56.5)$ & $\begin{array}{c}\text { 10.5, median } 1.97 \\
(0-35.5)\end{array}$ & $\begin{array}{c}\text { 23.2, median } 19.4 \\
(4.2-56.5)\end{array}$ \\
\hline
\end{tabular}


the percentage of patients with complex congenital heart defects and non-cardiac problems in the group of children who underwent hybrid and staged interventional therapies, as well as the number of AHASIT patients in the total population managed at the institution in the period. The AHASIT group was additionally divided into two main groups: group A patients for whom the hybrid procedure was definitive, final treatment, and group B - patients referred for a hybrid procedure as a stage in comprehensive, stage-planned treatment.

An individual preoperative severity scale was established for AHASIT patients. We summarized points related to all listed problems, with an equal number of one point for each clinical problem. Analyzed preoperative complications or non-cardiac problems were as follows: prematurity, low body weight, cyanosis, intolerance to drug therapy, failed interventional treatment prior to admission, mechanical ventilation prior to the procedure, chronic respiratory failure and non-cardiac, mainly congenital malformations (congenital diaphragmatic hernia $(\mathrm{CDH})$, lower extremity agenesia requiring orthopedic treatment, duodenal atresia) and acquired problems (newborn edema, necrotic enterocolitis (NEC), intracranial hemorrhage (ICH), liver and renal failure, anemia and thrombocytopenia, infections or colonization with drug-resistant pathogens). The maximum count of listed preoperative comorbidities in a patient used for further analysis was 16 points (100\%).

We analyzed the total number of interventions: each hybrid procedure, percutaneous intervention or a minor cardiovascular intervention (chest revision, pericardial or pleural drainage, peritoneal dialysis), and major postoperative complications: prolonged mechanical ventilation time and prolonged catecholamine administration (over $24 \mathrm{~h}$ ), multiorgan failure features and infections during the treatment until departure were summarized. We followed the rule to give an equal value of one point to each postoperative complication listed above.

The final results, the effectiveness of definitive treatment or staged strategy, prolonged complications, total mortality and survival time were analyzed in the group of alternative hybrid and staged interventional cases. The success of AHASIT therapy was both: a final good result of a definitive hybrid procedure and survival to the next, or final stage in the group of staged treatment. A good result in VSD patients was judged after placement of the occluder in the correct position with an acceptable residual (mild or trivial) shunt, without hemodynamic significance. The success of aortic or pulmonary artery stenting, or hybrid angioplasty, was judged as reduction of the initial gradient to $20 \mathrm{~mm} \mathrm{Hg}$, or below. Effective stenting of the duct, or other side-selective pulmonary banding, was assessed with color Doppler echocardiography (intraoperative, transoesophageal and transthoracic) and the final angiography.

The clinical outcomes, interventions and postoperative complications were finally matched with the retrospectively analyzed numeric preoperative severity scale (AHASIT severity score) of the patients.

\section{Outline of technical considerations: surgical, hybrid and interventional treatment}

The techniques of hybrid procedures designed for septal defects and single-ventricle pathologies were analogous with those previously reported by other authors, and are presented in our previous papers $[7,8]$. We used standard implants for septal defect closure (Amplatzer VSD Occluder (AGA Med. Corp., USA) or alternatively Amplatzer Duct Occluder II (AGA Med. Corp., USA)), pressure catheter balloons and Cook stents (Cook, EU) for PDA and pulmonary artery stenting. For the smallest and premature babies the only possible option was the use of coronary stents for PDA or aortic arch treatment. The surgical approach was a classic median sternotomy, miniinvasive lower ministernotomy, right anterior minithoracotomy for hybrid atrial septal defect (ASD) closure, and left thoracotomy for peripheral left pulmonary artery (LPA) stenting. The surgery was done after initial half-dose heparinization (1.5 mg per kg body weight (bw)) under fluoroscopy control with simultaneous transoesophageal (TEE) and epicardial (EE) echocardiography. The technique of percutaneous stenting of the pulmonary arteries, aorta, Kommerell's diverticulum and the interatrial communication (patent foramen ovale (PFO)) was regularly done in the cath lab from inguinal punctures. The final angiography (exit angio) was done routinely immediately after fluoroscopy-controlled arterial balloon angioplasty and direct stent implantation.

\section{Statistical analysis}

Distribution of relevant characteristics of the patients was described using mean and percentage 
with standard deviation (SD) and range for continuous and categorical variables, respectively. Quantitative data were reported in terms of absolute frequencies and percentages. Pearson goodness-of-fit $\chi^{2}$ test was used to analyze associations between independent variables. Value of $p<0.05$ was chosen as the cut-off point for significance. Statistical analysis was performed using SPSS v. 13.0 (SPSS Inc, USA).

\section{Results}

Hybrid and alternative interventional treatment was the definitive solution in 6 children (group A $27.2 \%$ ), while in 16 (group B $-72.8 \%$ ) cases it was

Table II. Preoperative and postoperative complications in AHASIT patients: staged approach group B $(n=16)$ versus definitive treatment group A $(n=6)$

\begin{tabular}{|c|c|c|c|}
\hline Feature & $\begin{array}{c}\text { Group A } \\
\text { Number (\%) - definitive }\end{array}$ & $\begin{array}{c}\text { Group B } \\
\text { Number (\%) - staged }\end{array}$ & Value of $p$ \\
\hline \multicolumn{4}{|l|}{ Preoperative complications: } \\
\hline Prematurity $(<38 \mathrm{Hbd})$ & $3(50)$ & $4(25)$ & 0.262 \\
\hline Low birth weight & $2(33.3)$ & $8(50)$ & 0.484 \\
\hline Perinatal infection & $2(33.3)$ & $4(25)$ & 0.696 \\
\hline Respiratory failure & $2(33.3)$ & $7(43.8)$ & 0.658 \\
\hline Cyanosis & $2(33.3)$ & $11(68.8)$ & 0.132 \\
\hline Low body weight & $2(33.3)$ & $9(56.3)$ & 0.338 \\
\hline Coarctation of aorta & $0(0)$ & $3(18.8)$ & 0.254 \\
\hline Diaphragmatic hernia & $0(0)$ & $2(12.5)$ & 0.364 \\
\hline Genetic syndrome & $3(50)$ & $3(18.8)$ & 0.142 \\
\hline Lack of thymus & $1(16.7)$ & $3(18.8)$ & 0.91 \\
\hline Non-cardiac surgical procedure & $3(50)$ & $6(37.5)$ & 0.595 \\
\hline Left heart hypoplasia & $0(0)$ & $5(31.3)$ & 0.119 \\
\hline Intolerance of pharmacological treatment & $3(50)$ & $10(62.5)$ & 0.595 \\
\hline Failed interventions before & $2(33.3)$ & $3(18.8)$ & 0.467 \\
\hline Mechanical ventilation & $0(0)$ & $5(31.3)$ & 0.119 \\
\hline Concomitant multiorgan failure & $3(50)$ & $6(37.5)$ & 0.595 \\
\hline \multicolumn{4}{|l|}{ Postoperative complications: } \\
\hline Total number of procedures & $\begin{array}{c}1 \text { procedure }-1(16.7) \\
2 \text { procedures }-3(50) \\
3 \text { procedures }-1(16.7) \\
4 \text { procedures }-1(16.7) \\
5 \text { procedures }-0(0) \\
6 \text { procedures }-0(0) \\
7 \text { procedures }-0(0)\end{array}$ & $\begin{array}{l}1 \text { procedure }-2(12.5) \\
2 \text { procedures }-4(25) \\
3 \text { procedures }-4(25) \\
4 \text { procedures }-1(6.3) \\
5 \text { procedures }-1(6.3) \\
6 \text { procedures }-3(18.8) \\
7 \text { procedures }-1(6.3)\end{array}$ & 0.752 \\
\hline $\begin{array}{l}\text { Mechanical ventilation up to } 24 \mathrm{~h} \\
\text { after procedure }\end{array}$ & $2(33.3)$ & $6(37.5)$ & 0.856 \\
\hline Prolonged catecholamine infusion & $1(16.7)$ & $9(56.3)$ & 0.097 \\
\hline Multiorgan failure symptoms & $0(0)$ & $6(37.5)$ & 0.079 \\
\hline Death & $0(0)$ & $6(37.5)$ & 0.079 \\
\hline
\end{tabular}


a part of staged therapy on the way to the final surgical procedure. The analysis of preoperative comorbidities and postoperative complications in both groups is presented in Table II.

The analysis of preoperative comorbidities and postoperative complications in both age groups (groups 1 and 2) is presented in Table III (Table IV).
There were 3 early deaths, within $24 \mathrm{~h}$ after the hybrid procedure (13.6\%) in the presented group, and 3 other patients (13.6\%) died in mid-term observation. The patients who died early after the procedure suffered from severe circulatory failure with a bad response to maximum medical therapy. Unfortunately there were clear contraindications to any mechanical

Table III. Preoperative and postoperative complications in AHASIT patients in the two age groups: group 1 (newborns) and group 2 (infants and older children)

\begin{tabular}{|c|c|c|c|}
\hline Feature & $\begin{array}{c}\text { Group } 1 \\
\text { Number }(\%)-\text { newborns } \\
(n=8)\end{array}$ & $\begin{array}{c}\text { Group } 2 \\
\text { Number }(\%)-\text { infants and } \\
\text { older children }(n=14)\end{array}$ & Value of $p$ \\
\hline \multicolumn{4}{|l|}{ Preoperative complications: } \\
\hline Prematurity $(<38 \mathrm{Hbd})$ & $2(25)$ & $5(357)$ & 0.604 \\
\hline Low birth weight & $6(75)$ & $4(28.6)$ & 0.035 \\
\hline Perinatal infection & $2(25)$ & $4(28.6)$ & 0.856 \\
\hline Respiratory failure & $5(62.5)$ & $4(28.6)$ & 0.119 \\
\hline Cyanosis & $5(62.5)$ & $8(57.1)$ & 0.806 \\
\hline Low body weight & $6(75)$ & $5(35.7)$ & 0.076 \\
\hline Coarctation of aorta & $0(0)$ & $3(21.4)$ & 0.159 \\
\hline Diaphragmatic hernia & $2(25)$ & $0(0)$ & 0.05 \\
\hline Genetic syndrome & $1(12.5)$ & $5(35.7)$ & 0.24 \\
\hline Lack of thymus & $2(25)$ & $2(14.3)$ & 0.521 \\
\hline Non-cardiac surgical procedure & $3(37.5)$ & $6(42.9)$ & 0.806 \\
\hline Hypoplastic left heart syndrome & $4(50)$ & $1(7)$ & 0.021 \\
\hline Intolerance of pharmacological treatment & $6(75)$ & $7(50)$ & 0.251 \\
\hline Failed interventions before & $1(12.5)$ & $4(28.6)$ & 0.387 \\
\hline Mechanical ventilation & $4(50)$ & $1(7)$ & 0021 \\
\hline Concomitant multiorgan failure & $4(50)$ & $5(35.7)$ & 0.512 \\
\hline \multicolumn{4}{|l|}{ Postoperative complications: } \\
\hline Total number of procedures & $\begin{array}{c}1 \text { procedure }-1(12.5) \\
2 \text { procedures }-3(37.5) \\
3 \text { procedures }-3(37.5) \\
4 \text { procedures }-0(0) \\
5 \text { procedures }-1(12.5) \\
6 \text { procedures }-0(0) \\
7 \text { procedures }-0(0)\end{array}$ & $\begin{array}{c}1 \text { procedure }-2(14.3) \\
2 \text { procedures }-4(28.6) \\
3 \text { procedures }-2(14.3) \\
4 \text { procedures }-2(14.3) \\
5 \text { procedures }-0(0) \\
6 \text { procedures }-3(21.4) \\
7 \text { procedures }-1(7)\end{array}$ & 0.367 \\
\hline $\begin{array}{l}\text { Mechanical ventilation up to } 24 \mathrm{~h} \\
\text { after the procedure }\end{array}$ & $3(37.5)$ & $5(35.7)$ & \\
\hline Prolonged catecholamine infusion & $6(75)$ & $4(28.6)$ & 0.035 \\
\hline Multiorgan failure symptoms & $5(62.5)$ & $1(7)$ & 0.005 \\
\hline Death & $6(75)$ & $0(0)$ & 0.001 \\
\hline
\end{tabular}


Table IV. Major indications for AHASIT treatment in different groups of procedures

\begin{tabular}{|lccc|}
\hline Main types of procedures & Number (\%) & $\begin{array}{c}\text { Group A (definitive) : } \\
\text { group B (staged) }\end{array}$ & Major indications for AHASIT treatment \\
\hline Closure of intracardiac defects & $5(22.7)$ & $4: 1$ & $\begin{array}{c}\text { Morphology of defect } \\
\text { Concomitant non-cardiac disorders }\end{array}$ \\
\hline $\begin{array}{l}\text { Stenting of the arterial duct } \\
\text { (PDA) }\end{array}$ & $7(32)$ & $0: 7$ & $\begin{array}{c}\text { Prematurity } \\
\text { Low birth weight } \\
\text { Respiratory failure }\end{array}$ \\
& $3(13.6)$ & $0: 3$ & $\begin{array}{c}\text { Congenital malformations } \\
\text { Sultiple surgical intervention } \\
\text { Stenting of pulmonary arter surgical repair }\end{array}$ \\
\hline $\begin{array}{l}\text { Stenting aortic arch and } \\
\text { coarctation }\end{array}$ & $3(13.6)$ & $1: 2$ & $\begin{array}{c}\text { Prematurity } \\
\text { Low birth weight } \\
\text { Respiratory failure }\end{array}$ \\
\hline $\begin{array}{l}\text { Improvement of interatrial } \\
\text { shunt and other }\end{array}$ & $4(18.2)$ & $1: 3$ & $\begin{array}{c}\text { Poor clinical condition } \\
\text { Concomitant non-cardiac disorders } \\
\text { Low body weight }\end{array}$ \\
\hline
\end{tabular}

circulatory support because of non-surgical bleeding. Two of 3 children lost in mid-term observation died because of severe infection (premature newborn with interrupted aortic arch (IAA) treated for pneumonia) and non-compensated multiorgan failure (3-year-old girl suffering from recurrent infections after initial treatment for $\mathrm{CDH}$ ). The longest survival time in the group of 6 children who died after AHASIT treatment was 36 months. The overall mortality in the presented group was $27.3 \%$. All patients who died were AHASIT children operated on as newborns (Figure 1), as well as naturally the patients from the "staged" group (Figure 2).

The mean count of overall invasive procedures (major and minor interventions) per patient was 3.5

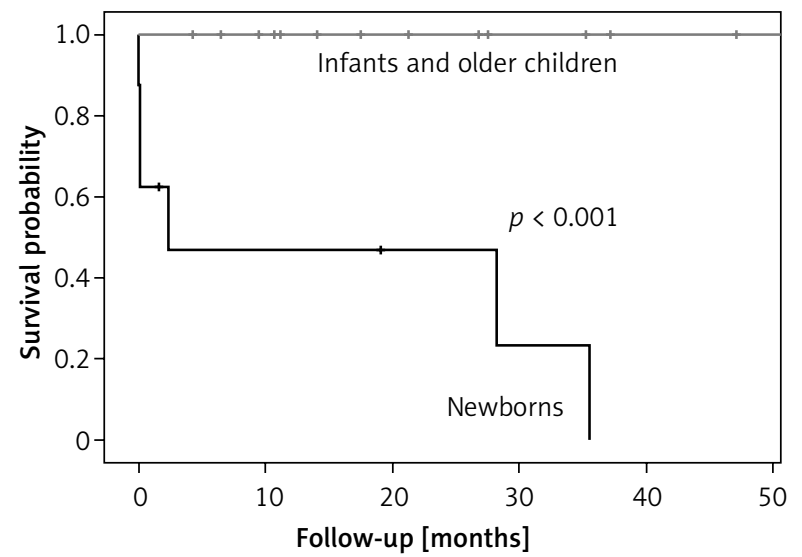

Figure 1. Survival of AHASIT patients: newborns (group 1) and infants and older children (group 2)
(SD $=2.1$; range: $1-8)$, while there were 3.2 major procedures per patient $(S D=1.8$; range: $1-6)$.

Prolonged duration of postoperative ventilation (more than $24 \mathrm{~h}$ ) was observed in 8 (36.4\%) children, while prolonged duration of catecholamine support was observed in $10(45.5 \%)$ patients. Postoperative multiorgan failure features were observed in 6 (27.3\%) children. There were no postoperative infections related to the hybrid or interventional treatment.

The mean preoperative AHASIT severity score of group 1 (newborns) was 6.63 points (SD = 2.6; range: $3-10$ ) while in group 2 (infants and older children) it was 4.6 points (SD $=3.2$; range: $1-11$ ), without statistical significance (Mann-Whitney $U$ test, $p=0.099)$; the respective percentages were as fol-

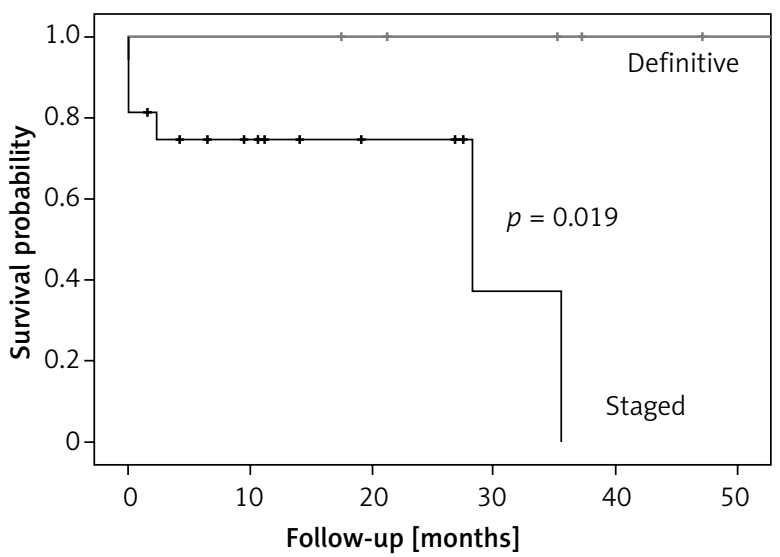

Figure 2. Survival of AHASIT patients: definitive treatment (group A) and staged approach (group B) 


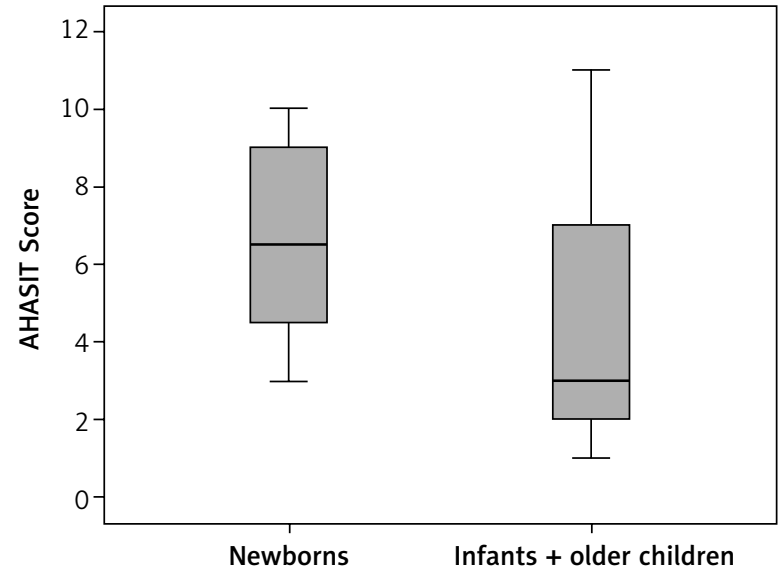

Figure 3. Box plots of the AHASIT preoperative severity score for newborns (group 1) and infants and older children (group 2)

lows: group $1-41.4 \%(\mathrm{SD}=16.3$; range: $19-63 \%)$ vs. group $2-29 \%$ (SD = 19.7; range: $6-69, p=0.099)$ (Figure 3). Mean preoperative AHASIT severity score in group $B$ (staged treatment) was 5.6 points $(S D=$ 3.4; range: $1-11$ ) while in group $A$ (definitive treatment) it was 4.7 points (SD $=2.1$; range: $3-8, p=$ $0.683)$; the respective percentages were as follows: group $B-35 \%(S D=21.3$; range: $6-69 \%)$ vs. group $A$ $-29 \%$ (SD = 12.9; range: $19-50 \%, p=0.683$ ).

Mean survival time was 42.2 months in group 2 ( $\mathrm{SE}=4.47,95 \% \mathrm{Cl}$, range: $33.7-51.2$ months) while in group 1 (newborns) it was 31.4 months (SE = 7.2; 95\% Cl, range: $17.3-45.5$ months, $p=0.184$ ).

The analysis of AHASIT severity score in the patients who survived showed 4.6 points $(S D=2.9$; range: $1-11)$, and in those who died 7.2 points (SD =

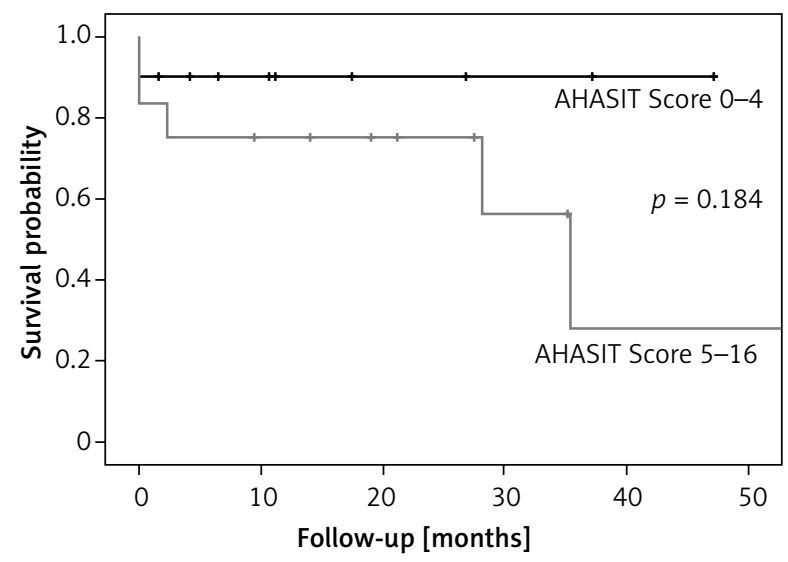

Figure 5. Comparison of survival with AHASIT score: group C (up to 4 AHASIT points) and group D (over 5 AHASIT points)

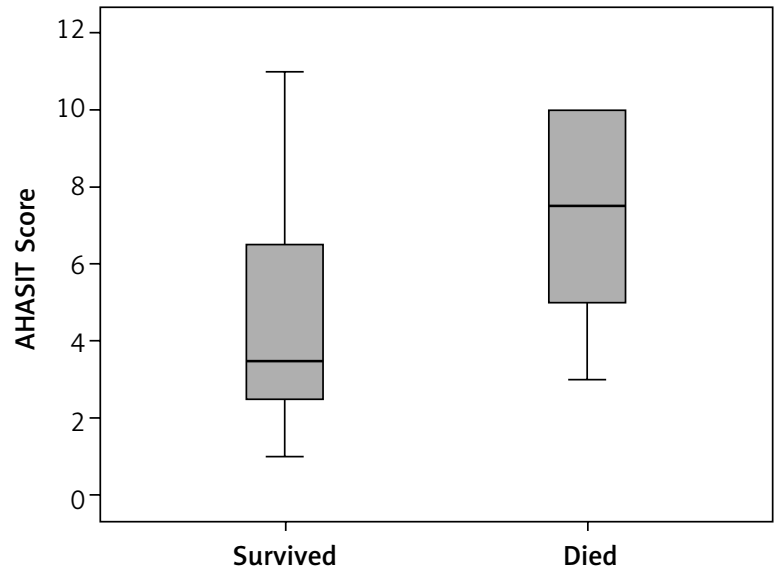

Figure 4. Box plots of the AHASIT preoperative severity score with overall survival

2.8; range: $3-10, p=0.081)$; the respective percentages were as follows: survived $29 \%$ (SD = 19; range: $3-10 \%$ ) vs. died 45\% (SD = 17; range: $19-63 \%, p=$ 0.081 ). The analysis of preoperative AHASIT severity score and survival is shown in Figure 4.

For the purpose of the analysis of the preoperative comorbidities and the survival, with postoperative complication rate, the patients were divided into two subgroups: group C with 0-4 AHASIT points (10 patients), and group D with 5 AHASIT points or more (12 patients) (Figure 5).

The analysis of postoperative course showed that the patients from group D (5 AHASIT points or more) had a more complicated postoperative course than the patients from group C. Mechanical ventilation longer than $24 \mathrm{~h}$ was noted in 8 patients (group D) vs. 0 in group $D(p=0.002)$, prolonged catecholamine use in 9 (group D) vs. 1 patient in group C ( $p=0.004$ ), and the symptoms of multiorgan failure appeared in 5 (group D) vs. 1 patient from group C $(p=0.162)$.

It is worth mentioning that only 4 patients from the whole analyzed group were discharged home after AHASIT procedures (18.1\%), while 15 children were transferred to other facilities (68.1\%) for further treatment.

\section{Discussion}

Contemporary cardiac surgery and interventional cardiology are inextricably linked together, despite both of them have separately established position in treatment of different congenital heart diseases. 
Transcatheter balloon atrioseptostomy as well as an interventional critical pulmonary valvular stenosis (PS) are currently used as the procedures of choice in newborns. Both interventions prove their superior effectiveness over any initial surgical treatment. Peripheral angioplasty with direct stent implantation is reported as an alternative to surgery in cardiovascular pathologies presented in newborns and small infants with an unfavorable general condition [1]. Occluders and coils have become a firstchoice standard in the treatment of different leftto-right shunt lesions in older patients, with their limitations related to body weight and troublesome peripheral vascular access in children with body weight less than $10 \mathrm{~kg}[4,9]$. Nonetheless, complex defects still persist in the spectrum of comprehensive surgical treatment, although single ventricle pathologies are supported with interventional techniques [10, 11].

Hybrid cardiac procedures prove their effectiveness in closure of septal defects, and therefore are reasonable alternatives to surgical or transcatheter closure of mVSD. Classic surgical or interventional percutaneous treatment in small children is related to well-known risk of significant complications and residual shunts. The main advantages of the hybrid approach for mVSD in complex children are closure of the defect under direct control, diminished risk of hemodynamic compromise, as well as simultaneous correction of other defects, such as: surgical closure of perimembranous VSD, pulmonary artery (PA) de-banding and PA surgical or balloon angioplasty. Hybrid closure of ASD is an option for children with contraindications for contemporarily preferred interventional closure (positional pathologies or anomalous systemic venous return) and for patients unsuitable for traditional surgical treatment (low body weight with neurologic or neurodevelopmental problems, structural defects of the chest and skeletal pathologies) [12].

In the presented series patients with VSD were referred for an AHASIT procedure because of the additional risk or inconvenience of a classic treatment. We achieved the success known as complete closure or hemodynamic relevance of the VSD in every referred patient, although we observed trivial to moderate residual shunts just after the procedure. This observation seems to be common in early observations reported by many investigators [1, 3, 9]. Although our group was primary borderline and suffered from additional morbidities, the results are similar to those presented in the multicenter study by Michel-Behnke et al. [9]. They reported a series of 26 muscular VSD patients (23 pediatric and 3 adults, mean pediatric age 6.7 months, mean bw: $5.8 \mathrm{~kg}$ ), who were referred for successful hybrid VSD closure with a history of additional cardiovascular problems (mainly TGA, DORV, Swiss-cheese VSD, and CoA). The main differences between the group reported by $\mathrm{Mi}$ chel-Behnke and our VSD children were the age and body weight at the time of the procedure (4 patients, mean age: 12.85 months, mean bw: $6.6 \mathrm{~kg}$ ), as well as the number of accompanying problems. The advantage of pre-banded children referred for postponed hybrid treatment was an elective, non-emergency treatment, without hemodynamic instability, which was a main inclusion criterion, and of course the risk factor for the patients presented in our analysis.

The hybrid strategy appeared to be beneficial for incidental emergencies such as implant migration after failed interventional PDA closure. The cooperation between the cardiac surgeon and interventional cardiologist makes possible miniinvasive removal of the migrated implant and effective PDA closure during a single approach procedure. This somewhat unusual solution of unexpected problems could provide new effective algorithms for difficult individual settings [13].

The early hybrid cardiovascular strategy following the principle of staged hybrid HLHS treatment could be effective in neonates with left-sided $\mathrm{CDH}$ and significant isolated left heart hypoplasia ( $\mathrm{LHH}$ ): direct stenting of the PDA and banding on the right pulmonary artery, with the goals to increase blood flow in the aorta and at the same time reduce right ventricle overload and pulmonary hypertension [14]. The concept follows the idea of hybrid operations performed as the first stage in the hybrid treatment of the hypoplastic left heart syndrome (HLHS): bilateral PA bandings with PDA stent implantation via the ministernotomy approach [2, 11]. Both operations improve the child's general condition, give time for the restoration of the left ventricle $(\mathrm{CDH})$ or prepare the newborn for the next stage: comprehensive HLHS hybrid stage II, or, in selected cases, for biventricular repair. In the group we performed an interventional re-stenting of ostially stenosed primary-stented PDA (telescope technique) that was found to be an effective, life-saving option for a HLHS baby after hybrid HLHS stage I [15]. 
In the group of single ventricle (SV) pathologies, balloon atrioseptostomy performed separately sometimes needs to be followed by direct stenting of the atrial septum in the area of foramen ovale (PFO) [1]. In the presented series we used this percutaneous balloon atrioseptostomy in five patients, although we want to emphasize that the strategy was ineffective in a patient with restrictive flow through a small and rigid PFO. The neonatal procedure of percutaneous balloon dilatation with direct PFO stent implantation (after initial BT shunt) was found to be an effective staged strategy. The stent was smartly removed while performing the Glenn shunt without any complications; finally the patient successfully completed the extracardiac total cavopulmonary connection (extracardiac TCPC) at the age of 2 years. The patients with single-ventricle pathophysiology were referred with more comorbidities (high AHASIT score), followed by a higher postoperative complication score, and of course predictable mortality [11].

Most of the patients with complex form of tetralogy of Fallot (ToF) present different degrees of hypoplasia of one or both pulmonary arteries, with rare pulmonary malformations called "discontinuous pulmonary arteries". The anomalous origin of the pulmonary artery branch needs to be anatomically corrected upon surgical intracardiac repair of ToF, while initial cardiology interventional treatment could be beneficial with the aim of recruiting (direct stenting), or widening (balloon angioplasty) pulmonary arteries. We used the percutaneous technique to widen an anomalous pulmonary artery origin, narrowed LPA from the aorta, and for direct stenting of the Kommerell's diverticulum that gave rise to the LPA [16]. We preferred percutaneous stent deployment in contrast to the report of Menon and co-workers, who implanted intraoperatively 27 stents in 24 patients, medium age 15 years, who were initially treated because of pulmonary atresia (PA - 9 cases) and ToF (7 cases) [17]. We followed the intraoperative concept for peripheral approach stenting of critical stenosis of the LPA in a 6.5 -year-old $20 \mathrm{~kg}$ bw boy after the correction of PA-VSD: the stent was successfully implanted after the left re-thoracotomy and regaining of the remnant stump of the initially occluded BT shunt.

Severely ill newborns with complex coarctation (CoA), multiorgan failure and severe general edema could be alternatively referred for emergency stent- ing of the isthmus, or transverse aortic arch stenosis apart from the typical coarctation area. The strategy of minimally invasive interventional bridging of a borderline newborn with COA is a continuation of the experience with stenting of native coarctations in older patients, or complex recurrent stenosis of previously surgically treated children. In the report of Pushparajah et al., who presented four-center experience with stenting of the proximal and distal aortic arch, the intervention was a final treatment for a much older common group of 21 patients (median age 16.5 years, median weight $55 \mathrm{~kg}$ ) [10]. The endpoints of their analysis were the improvement of local flow parameters gained from the catheterization and the reduction of hypertensive medication, and there was no need of further surgery in mid-term follow-up. As a difference, procedures performed in neonates presented in the analysis above (2 patients, age: 1 day and 3.5 months, body weight: $3.2 \mathrm{~kg}$ and $2.9 \mathrm{~kg}$ ) were performed as a temporary solution, and were followed by planned surgical stent removal and repair of the arch (correction of complex CoA and complex ToF with arch stenosis) after stabilization of the general condition of the children.

The strategy of a hybrid approach based on hybrid HLHS treatment was used for a staged approach for a critically premature newborn with IAA type B. The direct PDA stent implantation was a temporary solution to postpone major surgery that was contraindicated in the $1.8 \mathrm{~kg}$ baby, similarly to the concept presented in three cases by Valeske [18].

The limitations of the study are the small number of patients involved and relatively short followup period. We honestly reported the high mortality ( 3 early, and 3 mid-term deaths), but it should be borne in mind that the bad results were obtained in critically ill children who could not meet the criteria for any standard therapeutic option (medical, surgical or interventional). Thus the reported mortality was not primarily related to the cardiac problem itself, and undertaken treatment. Therefore our questionable results in this group outline our clinical attempts to provide any acceptable solution for 'non-option patients'. After the meticulous analysis there are possible some initial conclusions that a staged approach in newborns before 30 days after birth are the risk factors of earlier or interstage mortality, and limit the survival. The youngest children included in the analysis exhibited in fact the highest extent of comorbidities defined by AHASIT points. We found 
that in the most severe and the smallest children the AHASIT strategy allowed us to wait until the next stage for $60 \%$ of newborns, regardless of severe comorbidities and critical condition. Despite the fact that we did not reach any statistical significance, the AHASIT score, although prepared for the purpose of this particular study, seems to be promising, and potentially a valuable prognostic factor in the future [19-21]. The value of the analysis improves the complete data of consecutively managed patients, who were referred for hybrid and interventional emergencies, with concomitant growing experience of the heart team [22]. There is an unquestionable need to enlarge the group as well as to continue the follow-up to obtain more data that will empower the analysis to reveal any statistical significance.

\section{Conclusions}

Alternative hybrid and staged interventional treatment of pediatric congenital heart defects with complex and non-cardiac problems appeared to be an attractive option for selected severely ill patients. The strategy of a miniinvasive interventional bridge to postpone, or continue major surgical repair appeared to be effective in selected neonates suffering from complex and accompanying non-cardiac pathologies, with positive final results of both cardiology intervention and planned surgery. We wish to stress that the presented strategies, although used with conscience in extremely suboptimal circumstances, gave in our experience a reasonable last chance solution of critical cardiac problems with acceptable results.

\section{Conflict of interest}

The authors declare no conflict of interest.

\section{References}

1. Shranz D, Michel-Behnke I. Advances in interventional and hybrid therapy in neonatal congenital heart disease. Seminar Fetal Neonatal Med 2013; 18: 311-21.

2. Galantowicz M, Cheatham JP, Philips A, et al. Hybrid approach for hypoplastic left heart syndrome: intermediate results after the learning curve. Ann Thorac Surg 2008; 85: 2063-71.

3. Holzer R, Marshall A, Kreutzer J, et al. Hybrid procedures: adverse events and procedural characteristics - results of a multi-institutional registry. Congenit Heart Dis 2010; 5: 233-42.

4. Knop M, Szkutnik M, Fiszer R, et al. Transcatheter closure of atrial septal defect in children up to $10 \mathrm{~kg}$ of body weight with Amplatzer device. Cardiol J 2014; 21: 279-83.
5. Haponiuk I, Chojnicki M, Jaworski R, et al. Hybrid approach for closure of muscular ventricular septal defects. Med Sci Monit 2013; 19: 618-24.

6. Haponiuk I, Chojnicki M, Jaworski R, et al. Hybrid cardiovascular procedures in the treatment of selected congenital heart disease in children - a single-centre experience. Kardiol Pol 2014; 72: 223-9.

7. Chojnicki M, Haponiuk I, Jaworski R, et al. Intraoperative imaging of hybrid procedure for muscular ventricular septal defects closure with Amplatzer Duct Occluder II. Kardiol Pol 2011; 69: 1280-1.

8. Haponiuk I, Chojnicki M, Jaworski R, et al. Delayed closure of multiple muscular ventricular septal defects in an infant after coarctation repair and a hybrid procedure - a case report. Heart Surg Forum 2011; 4: E67-9.

9. Michel-Behnke I, Ewert P, Koch A, et al. Device closure of ventricular septal defects by hybrid procedure: a multicenter retrospective study. Catheter Cardiovasc Interv 2011; 77: 242-51.

10. Pushparajah K, Sadiq M, Brzezińska-Rajszys G, et al. Endovascular stenting in transverse aortic arch hypoplasia. Catheter Cardiovasc Interv 2013; 82: E491-9.

11. Venugopal PS, Luna KP, Anderson DR, et al. Hybrid procedure as an alternative to surgical palliation of high-risk infants with hypoplastic left heart syndrome and its variants. J Thorac Cardiovasc Surg 2010; 139: 1211-5.

12. Haponiuk I, Chojnicki M, Jaworski R. Comment to article: Hybrid, perventricular closure of muscular ventricular septal defects. Kardiol Pol 2013; 71: 211.

13. Haponiuk I, Chojnicki M, Jaworski R, et al. Miniinvasive hybrid procedure for device migration after percutaneous closure of persistent arterial duct: a case report. Videosurgery Miniinv 2012; 7: 202-5.

14. Sroka M, Haponiuk I, Chojnicki M, et al. Cardiovascular hybrid procedure in severe congenital diaphragmatic hernia with significant left heart hypoplasia. Eur J Cardiothorac Surg 2012; 42: 185-7.

15. Chojnicki M, Haponiuk I, Jaworski R, et al. Proximal ductus arteriosus stenosis after the hybrid stage I procedure in a newborn with hypoplastic left heart syndrome. Postep Kardiol Inter 2013; 9: 187-9.

16. Juściński J, Haponiuk I, Chojnicki M, et al. Operative treatment of tetralogy of Fallot with concomitant correction of anomalous origin of the left pulmonary artery from Kommerell's diverticulum. Kardiochir Torakochir Pol (in press).

17. Menon SC, Cetta F, Dearani JA, et al. Hybrid intraoperative pulmonary artery stent placement for congenital heart disease. Am J Cardiol 2008; 102: 1737-41.

18. Valeske K, Mueller M, Hijeh N, et al. Modified repair of interrupted aortic arch utilizing retroesophageal right subclavian artery based on a neonatal hybrid approach in hypoplastic left heart complex. Thorac Cardiovasc Surg 2012; 60: 221-5.

19. Kansy A, Maruszewski B, Jacobs J, et al. Application of four complexity stratification tools (Aristotle Basic Score, RACHS-1, STAT, Morality Score, and STAT Mortality Categories) to evaluate early congenital heart surgery outcomes over 16 years at a single institution. Kardiochir Torakochir Pol 2013; 10: 115-9. 
20. Gutgesell HP, Lim DS. Hybrid palliation in hypoplastic left heart syndrome. Curr Opin Cardiol 2007; 22: 55-9.

21. Pizarro C, Derby CD, Baffa JM, et al. Improving the outcome of high-risk neonates with hypoplastic left heart syndrome: hybrid procedure or conventional surgical palliation? Eur J Cardiothorac Surg 2008; 33: 613-8.

22. Haponiuk I, Chojnicki M, Jaworski R, et al. Short communication Gdansk Hybrid Heartlink Programme (GHHP) - we need to share the experience with miniinvasive hybrid procedures in borderline babies. Videosurgery Miniinv 2013; 8: 238-40.

Received: 9.12.2014, accepted: 25.01.2015 